*Pós-graduado em DIREITO CONSTITUCIONAL e DIREITO DO TRABALHO. Advogado. Contato: guilhermelvalerio@gmail.com.

**Doutor em Direito Político e Econômico pela Universidade Presbiteriana Mackenzie, Mestre em Direito Negocial pela Universidade Estadual de Londrina, Advogado e autor de livros.

\section{Abstrativização Do Controle Incidental, A Eficácia das decisões e a Mutação Constitucional Do Art. 52, X DA CF: Uma Resposta Às Críticas}

\author{
Abtractization Of Incidental Constitutional \\ Control, The Effectiveness Of Decisions And The \\ Constitutional Mutation Of Article 52, X Of \\ BraziL's CONTITUTION: A RESPONSE For CRITICISM
}

\author{
Guilherme Lucas Valério* \\ Fábio Fernandes Neves Benfatti**
}

Como citar: VALÉRIO, Guilherme Lucas; BENFATTI, Fábio Fernandes Neves. Abstrativização do controle incidental, a eficácia das decisões e a mutação constitucional do art. 52, X da CF: uma resposta às críticas. Revista do Instituto de Direito Constitucional e Cidadania - IDCC, Londrina, v. 5, n. 1, p 111127, jan/jul, 2020. ISSN: 2596-0075.

https://doi.org/10.48159/revistadoidcc.v5n1.valerio.benfatti

Resumo:O trabalho procura responder às críticas sobre a mutação constitucional do artigo $52, \mathrm{X}$ da $\mathrm{CF}$, compreensão que fora pensada por parte da doutrina e encampada pelo STF em sua composição atual. A interpretação do inciso propõe a sistematização das decisões do tribunal e seu consequente respeito independentemente de o processo ser objetivo ou incidental. Apesar disso, não se pode esquecer acerca de alguns institutos existentes no direito pátrio, motivo pelo qual não podem ser desmaterializados. Para tanto, introduzimos o assunto com os conceitos mais importantes para a compreensão do tema de controle de constitucionalidade e a mutação constitucional, seguida do papel dos poderes nesse controle e a exposição de todas críticas relevantes que infirmam a referida posição. Como consequência do objetivo, o artigo propõe uma tentativa de harmonização dessa mutação com o sistema de controle de constitucionalidade existente, bem como a própria constituição, com a valorização do precedente como ferramenta para evolução jurisprudencial.

Palavras-chave: Controle de constitucionalidade, abstrativização 
do controle incidental, art. 52, $\mathrm{X}$ da CF.

Abstract:The work finds an answer for the criticism about the constitutional mutation of article 52, X in Brazil's Constitution position thought by part of the doctrine and endorsed by the Supreme Court in your current composition. The comprehension proposes made a system from the decisions of the Court to be respected from objective or incidental control. In spite of that, one cannot forget about some existing institutes in the national law, reason why they cannot be dematerialized. For the purpose, introduces the definitions and more important concepts for the main theme followed about constitutional control and constitutional mutation, followed by the performance of each power in constitutional control and the exposed of all criticism that reduces the importance of this meaning. By the consequence of this, the article pretends a harmonic understanding of the mutation and the current constitutional control system by an appreciation of precedent as an evolutional jurisprudential tool.

Keywords: Constitutional control, abstractization of incidental constitutional control, art. 52, X of Brazil's Constitution. 


\section{INTRODUÇÃO}

Nos países que adotam a teoria Kelseniana como suporte constitucional, há limites estabelecidos nos quais todos os poderes devem respeitar pois decorrem da própria natureza do Estado Democrático de Direito. Ao garantir as instituições, a carta mantém o complexo jurídiconormativo por um árduo trabalho de respeito e orientação por aquilo que fora objeto da vontade de um povo estampada nesse documento maior.

Nesse contexto se insere a nova concepção sobre o modo como se garante a estabilidade da estrutura constitucional brasileira, que também adota o modelo Kelseniano, pelo controle de constitucionalidade das normas sustentada primordialmente pelo Poder Judiciário em sua atividade típica.

Assim, para garantir essa estabilidade e reforçar a confiabilidade no sistema, o Poder Judiciário procura mecanismos para garantir a autoridade de suas decisões e meios de integrar a aparente contradição entre as normas do sistema jurídico. Para tanto a existência da hermenêutica constitucional é essencial para a manutenção da respiração constitucional e sua conexão com a realidade, garantida pela integração.

$\mathrm{O}$ artigo irá analisar a nova compreensão do art. 52, X da CF e sua compatibilidade com as normas do sistema constitucional brasileiro, bem como a integração com outros institutos já existentes que pretendiam resolver o problema da respeitabilidade das decisões do tribunal supremo constitucional e que possuem a mesma tarefa. Para tanto, compreenderemos o contexto, as críticas e, depois, a posição.

\section{O CONTROLE DE CONSTITUCIONALIDADE NO BRASIL E A MUTAÇÃO CONSTITUCIONAL}

\section{a. O controle de constitucionalidade}

A relação de controle de constitucionalidade mantém estrita conexão com a ideia de rigidez constitucional e, assim, inegável a contribuição de Kelsen (2006) quando atribui à Carta Fundamental o papel de protagonista da estrutura jurídica, principalmente quando dá sentido as normas delas decorrentes por meio do princípio da compatibilidade vertical. Em consequência, há controle de constitucionalidade quando a norma constitucional não puder ser alterada por uma lei infraconstitucional ordinária ${ }^{1}$. Em apertada síntese, define-se controle da constituição, nas palavras de Dantas (2018, p.179):

O controle de constitucionalidade consiste justamente na fiscalização da adequação (da compatibilidade vertical) das leis e demais atos normativos editados pelo Poder Público com os princípios e regras existentes em uma constituição rígida,

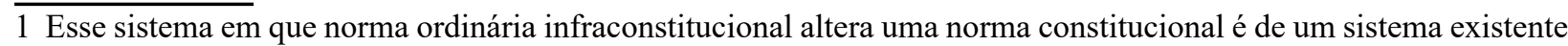
no processo de constituição flexível.
} 
para que se garanta que referidos diplomas normativos respeitem, tanto no que se refere ao seu conteúdo, quanto à forma como foram produzidos, os preceitos hierarquicamente superiores ditados pela carta magna.

A atividade de integridade e sustentação normativa constitucional é, acima de tudo, institucional, pois visa a manter o sistema íntegro e não propriamente de decidir sobre casos particulares. No Brasil, o controle de constitucionalidade é atividade típica do Poder Judiciário e pode ser de duas espécies: pela via principal ou pela via incidental.

Controle pela via principal seria aquele realizado por um órgão judicial, ou poucos, com atividade principal de análise da constitucionalidade da norma em si (material) ou o modo de sua construção (formal) com o objetivo de harmonizar o sistema em lide de caráter objetivo, sem partes, mas com legitimados institucionais (BARROSO, 2016). Historicamente foi a Constituição Austríaca consagrou a existência de um Tribunal Constitucional com exclusividade para o exercício de controle judicial de constitucionalidade, apoiado em Hans Kelsen e na rigidez constitucional, diverso do sistema americano (MORAES,2017).

Para esclarecer, importante separar que o controle pela via principal seja sinônimo de controle concentrado, pois nem sempre são coincidentes. O primeiro diz respeito ao número e papel dos órgãos para o controle de constitucionalidade; já o segundo compreende o objeto - análise da constitucionalidade de uma lei de modo abstrato, ou seja, somente pela análise normativa em si. Um exemplo para diferenciar as situações é a ação de intervenção ${ }^{2}$ em que há a utilização da via principal, mas se trata de um controle do caso concreto e não em abstrato.

Por outro lado, há o controle realizado pela via incidental. Classicamente, originou-se no caso Madison versus Marbury nos EUA. Nessa espécie o controle é uma questão prejudicial ao pedido principal, obstáculo necessário para o julgamento concreto da causa. Do mesmo modo, não há que confundir controle pela via incidental - apreciação de uma questão prejudicial em um caso concreto- com controle difuso - desempenhado por qualquer juiz ou tribunal em sua atividade regular. A regra é que eles sejam sinônimos, mas há a exceção: a arguição de descumprimento de preceito fundamental que trata de um controle incidental concentrado (BARROSO, 2016).

Compreendida as definições, importante ressaltar os efeitos que cada modalidade sustenta. De acordo com Barcellos (2018), o controle difuso-incidental declarado no contexto de uma demanda afeta as partes litigantes e suas pretensões, mas essa aplicação de constitucionalidade não faz coisa julgada e não impacta sobre a vigência da norma em abstrato em relação a todos os outros litigantes e processos; já nos casos de controle abstrato-concentrado, em oposição, formarse-á coisa julgada em relação aos pedidos e a própria decisão, valendo-se erga omnes, portanto, em consideração a atividade institucional do controle e em razão de o pedido principal ser a análise da sua constitucionalidade.

Por outra razão, importante não confundir o alcance dos efeitos com a sua consequente modulação. No primeiro caso, a relação é de extensão subjetiva; no segundo, se relaciona com a decisão e a partir de qual momento (temporal) ela poderá ser aplicada, se com efeitos retroativos

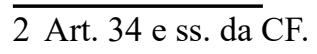


(ex tunc), ou efeitos prospectivos (ex nunc).

Com relação aos legitimados para sua propositura, pela via principal, o art. 103 da CF define seu rol que se repete em todas essas modalidades de controle no direito brasileiro ${ }^{3}$, exceto na ação direta de inconstitucionalidade interventiva que tem uma previsão particular no art. 34 da CF e Lei $n^{0}$ 12.562/11. Conforme vimos, a limitação de legitimados para o controle principal justificase pelo caráter institucional da sua natureza e assim é limitada a órgãos e entidades (BARROSO, 2016). Doutro lado, pela via incidental, como se trata de um processo judicial em que o controle é questão prejudicial, qualquer sujeito que possua capacidade processual poderá argui-la.

Diante do panorama geral sobre o controle de constitucionalidade, modalidades, origem, seus efeitos, legitimados e compreensão no direito brasileiro, passamos a frente.

\section{b. Mutação constitucional}

A Constituição não é um texto estático pois reproduz a ideia de um povo em determinado momento da história e, nesse sentido, para manter sua força e integridade, também a interpretação deve possuir respaldo social. Compreender como as ideias evoluem, a partir do texto e da história, é essencial para compreensão da noção de mutação constitucional.

Nos dizeres de Sarlet (2017) uma das funções do documento constitucional é assegurar estabilidade das instituições políticas e jurídicas reforçada pela rigidez constitucional, embora alterála não diminua tal sustento. Assim, em um ambiente marcado por essa modalidade de estabilidade constitucional pode-se alterá-la por meio dos mecanismos formais de mudança previstos em seu próprio texto, ou seja, as emendas constitucionais; ou pelos mecanismos informais, não previstos no texto, chamados de mutações constitucionais ou mudanças tácitas, definidos, de modo simples, como uma alteração do sentido da norma sem necessidade de modificação textual. Bulos (1996, p. 25-43) delimita da seguinte forma:

Assim, denomina-se mutação constitucional, o processo informal de mudança da Constituição, por meio do qual são atribuídos novos sentidos, conteúdos até então não ressaltados à letra da Lex Legum, quer através da interpretação, em suas diversas modalidades e métodos, quer por intermédio da construção (construction), bem como dos usos e costumes constitucionais. (...) A experiência constitucional dilucida que o fenômeno da mutação constitucional independe da rigidez do Texto Magno. Tanto as cartas rígidas como as flexíveis estão sujeitas ao influxo de novos sentidos, novos significados, que, embora não mudem a letra dos preceptivos supremos do Estado, conferem-lhes conteúdos ainda não contemplados, quer através da interpretação e da construção judicial, quer por meio dos usos e dos costumes constitucionais.

Tal compreensão não é momentânea, mas sim uma construção, um entendimento reiterado e consolidado que o tempo edifica e, apesar disso, não quer dizer que não há limites. O sentido

$3 \mathrm{Na}$ ADPF (Art. 2 , I da Lei no 9.882/99); em ADIn, ADIn por Omissão e ADC (Art. 2º e 12-A da Lei no 9.868). 
atribuído deve ser conduzido pela própria constituição como um sistema- um tribunal colegiado é composto de vários membros, nenhum magistrado tem, per si, a competência e autoridade de atribuir a definição do que entende ser o direito, pois o entendimento que irá prevalecer é do todo seja como um consenso ou maioria. A própria composição do tribunal seria suficiente para essa diversidade de ideias que não só oxigena a compreensão constitucional como acrescenta solidez a compreensão ao compor um sistema mais representativo. Por essa razão não se pode interpretar a mutação como razão antidemocrática.

Quando há a mutação constitucional e sua alteração de sentido, não se trata de uma modificação no texto constitucional, que se mantém intacto, mas sim compreende-se uma mutação no sentido do texto e seu modo de interpretar perante o sistema jurídico como um todo integrativo.

Nesse entendimento, interpretar uma norma constitucional e atribuí-la razão orientada pela constituição e à realidade fática momentânea, é papel da chamada mutação constitucional, sem que o texto, em si, seja modificado.

\section{O papel do Legislativo no controle de constitucionalidade e art. 52, $\mathrm{X}$ da CF}

Compreendidas as ideias gerais sobre controle de constitucionalidade e as possibilidades de alteração da constituição rígida, passemos a analisar o caso específico do ordenamento brasileiro e o modus operandi do controle de constitucionalidade.

$\mathrm{O}$ art. 52, inciso X da CF dispõe: “Art. 52. Compete privativamente ao Senado Federal: $X$ - suspender a execução, no todo ou em parte, de lei declarada inconstitucional por decisão definitiva do Supremo Tribunal Federal;".

A atribuição contida no artigo compreende caso em que o STF decida incidentalmente (vimos que no principal o efeito é além das partes) eventual interpretação normativa com incumbência de o Senado atribuir a ela efeitos erga omnes suspendendo a execução da lei por meio de resolução legislativa. Isso porque no controle abstrato o efeito já é erga omnes sem a necessidade de intervenção do Senado.

Historicamente, a intervenção do Senado tem origem no direito norte-americano, isto porque lá as decisões dos tribunais superiores são vinculantes aos demais órgãos- em razão do stare decisis (BARROSO, 2016). Porém, as decisões dos tribunais superiores por aqui não são congruentes ao modo como se opera nos Estados Unidos da América. Desta forma, o conceito do stare decisis não fora incorporado e a alternativa, diante dessa lacuna de os tribunais supremos conferirem determinada interpretação a uma decisão sem que ela tenha algum efeito além das partes, foi conferir atribuição da suspensão ao Senado, como visto.

Em relação a suas características, temos algumas peculiaridades. Primeiro, como afirma Moraes (2017), pacífica é a doutrina de que o Senado não está obrigado a editar tal resolução e, 
em consequência, os efeitos da resolução são ex nunc ${ }^{4}$, justamente porque a redação do artigo diz "suspender" e não trata de negar sua vigência desde sua produção. Assim, a resolução do Senado não revoga a lei/decreto, ela simplesmente suspende a execução - opera no plano da eficácia e não da validade, as relações anteriores à resolução serão apreciadas em cada caso concreto (SLAIBI FILHO, 2009). Por óbvio, caso o Senado decida pela suspensão, deve fazer nos termos do que fora decidido pelo STF (em relação a parte que pretende suspender a execução). Sobre isso, pondera Martins (2006) que caso ocorra eventual prejuízo pela forma como fora feita a suspensão, sua eventual ausência, ou mesmo eventual inexistência de modulação dos efeitos, deva ser questionado judicialmente.

Como meio de operar, Streck (2019) explica a diferença entre "suspensão da execução" da lei e "retirar a eficácia da lei" - atributo essencial para compreender a diferença entre controle difuso e concentrado de constitucionalidade. Assim, uma coisa é a lei deixar de ser executada, pois suspensa, outra é retirá-la do ordenamento por complexo e eliminar sua existência. Reforça Simão (2015) que esse papel não é somente conferir eficácia geral, pois os outros sujeitos não são afetados pela coisa julgada, a finalidade do instituto é retirar eficácia da lei. Quinaud Pedron (2015) compreende da mesma forma que esse papel do Senado não analisa somente a questão da legalidade, mas em conjunto com a doutrina, a sociedade, entre outros fatores políticos (natureza do dispositivo). Assim, o caráter é político, porque não há a possibilidade de represália em razão de inércia do Senado.

Mas, questiona-se: o Senado, e o legislativo como um todo, tem alguma relevância no controle de constitucionalidade além desse art. 52, X?

Sim. O Poder Legislativo poderá participar do controle de constitucionalidade em dois momentos: preventivamente ou de modo posterior à construção da norma. Primeiro, trata de um controle prévio (a priori) no projeto de norma- quando ela ainda está em formação. Por meio do controle preventivo, o poder legislativo, em ambas as casas, analisa a constitucionalidade do projeto de lei por meio da Comissão de Constituição e Justiça (CCJ) que tem esse como seu princípio fundamental de existência ${ }^{5}$. Segundo, em controle pós formação normativa, poderá realizá-lo por meio da sustação dos atos normativos editados pelo Poder Executivo- art. 49, V da CF ou quando veta determinada Medida Provisória editada que entende inconstitucional -art. $62 \S 5^{\circ}$ da CF.

Por essa consequência e conclusão, percebe-se que em ambos os casos o Poder Legislativo exerce um papel ativo na manutenção da estabilidade constitucional, e reforça o sistema de freios e contrapesos, diante da sua relevância e densidade. Deste modo, eventual argumento que um novo entendimento desse inciso implicaria em diminuição da participação do poder legislativo no controle de constitucionalidade é vazio.

4 Nesse sentido: MORAES, Alexandre de, Direito Constitucional, 33a ed. rev. e atual., São Paulo: Atlas, 2017, p. 526; MARTINS, Flávio, Curso de Direito Constitucional, 1a ed., São Paulo: Editora, Revista dos Tribunais, 2017, p. 592; DANTAS, Paulo Roberto de Figueiredo, Direito Processual Constitucional, $8^{\mathrm{a}}$ ed., São Paulo: Saraiva Educação, 2018, p. 205.

5 Regimento Interno da Câmara dos Deputados em seu artigo 53, III e o Regulamento do Senado no Art. 101, I. 


\section{A abstrativização do controle incidental de constitucionalidade ou abstração do controle difuso de constitucionalidade}

Até agora compreendemos o aspecto geral sobre o controle de constitucionalidade e, principalmente no Brasil, os meios de se alterar a constituição tanto formais quanto informais e o papel do poder legislativo nesse processo com a apresentação principal do inciso $\mathrm{X}$ do art. 52 da CF. Passemos agora a abordar um conceito recente sobre a tentativa de o Poder Judiciário interpretar a constituição e organizar o sistema jurídico com o objetivo de atribuir maior igualdade às decisões ao dar maior segurança jurídica aos jurisdicionados por atribuir um entendimento uniforme quanto a determinada questão jurídica independentemente do modo pelo qual tal questão chegou ao tribunal supremo.

Para compreensão do que se entende por abstrativização, Mendes (2017, p.881, 1037 e ss.), principal voz junto com Lucio Bittencourt, temos:

Em outros termos, se o STF declara, em caráter incidental, a inconstitucionalidade de norma em dado processo e, ao mesmo tempo, afirma que aquela decisão repercutirá ou será aplicada de determinada forma em outras situações, está a reconhecer a eficácia transcendente de sua decisão independentemente de intervenção do Senado.

Porém, não se pode confundi-la com a transcendência dos motivos determinantes que em conceito pretende atribuir eficácia aos motivos da decisão e não somente do dispositivo, ao passo que a abstrativização atribui eficácia geral ao que fora decidido (dispositivo) em relação a um processo específico objeto de controle incidental (PAULO, 2016). Muito embora alguns autores pensam que a consequência dessas duas situações é indissociável - havendo abstração do controle concreto, haverá, por consequência a transcendência dos motivos em razão da própria natureza do recurso extraordinário.

Historicamente a questão da abstrativização teve uma evolução. Em princípio, o STF possuía um precedente por manter a literalidade do artigo quando do julgamento da Reclamação n. 4.335-AC ${ }^{6}$. Na ocasião, o Min. Gilmar Mendes, voto vencido, ponderava que a função do Senado é eminentemente histórica com efeito de dar publicidade e cita a mutação constitucional para a alteração da interpretação. Em seu fundamento, mostrou um precedente do tribunal em que a declaração de constitucionalidade em sede de recurso extraordinário fez manifestamente improcedentes ações diretas que versavam sobre a mesma questão ${ }^{7}$. A compreensão sustenta a força da decisão submetida a critério do supremo, independentemente do modelo adotado no controle de constitucionalidade. Nos dizeres de Barroso (2016) manter a interpretação literal do inciso é um ser anacrônico após a vinda da CF/88.

Em 2017, o tribunal fora posto à prova pela discussão iniciada pelo Min. Alexandre de

6 BRASIL. Supremo Tribunal Federal, Rcl No 4335 AC, rel. Min. Gilmar Mendes, Data de Julgamento: 20/03/2014. 7 Precedente: BRASIL, Supremo Tribunal Federal, ADI No 4071 AgRg/DF, rel. Min. Menezes Direito, Data de julgamento: 22.04.2009. 
Moraes nas ADI 3406 e ADI 3470 que, apesar de ser realizado em controle principal, trouxe à tona $\mathrm{o}$ art. 52, X da CF novamente ${ }^{8}$. Com o mesmo esforço, Mendes reafirmou sua interpretação, mas a manteve por outro argumento ao justificar que o STF pratica a modulação de efeitos em sede de controle incidental - o que só faria sentido quando o tribunal pretende que seus votos sejam reproduzidos em outros julgados e respeitados de modo vinculante em todo o território nacional e órgãos da República.

Conforme expusemos, abstrativação do controle incidental pretende atribuir efeito erga omnes às decisões em controle incidental sem a necessidade da declaração do Senado Federal, conforme literal disposição do art. 52, X da CF. Essa mudança de entendimento do inciso desse artigo não só tem importância na estruturação do sistema jurídico ao garantir igualdade no tratamento da mesma questão jurídica, como também admite o respeito às decisões das cortes superiores e uniformiza a jurisprudência como um todo. Porém, tal condição e consequência possui muitas críticas. A seguir vamos expor todas as críticas elencadas por artigos, doutrina e as discordâncias acerca da posição adotada pelos ministros.

\section{Uma resposta às críticas da abstrativização do controle incidental}

Conforme expusemos, a posição clássica é de respeito ao inciso e inexistência de mutação ao caso9 ${ }^{9}$ São vários os autores que intitulam severas críticas pela mutação do inciso X do art. 52. Algumas mais vagas, outras precisas.

Por uma razão didática, optamos por expor todos os argumentos contrários para ao final, em um todo, respondê-los de maneira incisiva.

Começando, Dimoulis (2016), por exemplo, pondera três consequências sobre o dispositivo. Na primeira, cita os problemas entre mesclar o controle abstrato e o concreto. Apesar de reconhecer as dificuldades em misturar ambos e o excesso de trabalho do tribunal supremo federal, argumenta que seriam possíveis dois entendimentos por essa consequência- admitir o modo clássico de efeitos de cada controle ou "criar" novas regras de competência contrárias ao texto constitucional do art. 52, X, como um poder autocriativo. Porém, essas interpretações autocriativas do STF, ao fim e ao cabo, alteram o texto constitucional e esta é a segunda consequência. Como o dispositivo não deixa claro em qual modalidade de controle ele seria possível, a interpretação sugere que somente seria possível esse controle de maneira incidental e concreta. Por fim, o autor rebate a mutação constitucional como método de interpretação e afirma que não houve efetiva

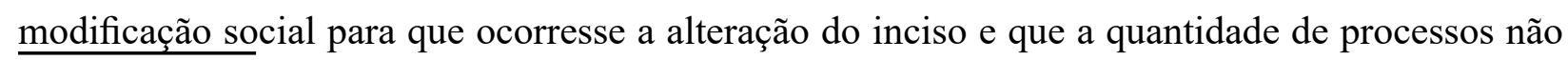

8 BRASIL, Supremo Tribunal Federal, ADI No 3406/RJ e ADI No 3470/RJ, rel. Min. Rosa Weber, Data de julgamento: 29.11.2017. No caso em tela, discutiram sobre a interpretação do art. 52, X da CF tendo os Ministros Alexandre de Moraes, apesar de sua ressalva de não ter se manifestado expressamente sobre a questão, e Marco Aurélio Mello pela interpretação literal da Constituição, ao passo que o Min. Gilmar Mendes, Luiz Fux, Celso de Mello, Cármen Lúcia, Edson Fachin e Dias Toffoli, entenderam pela mutação constitucional acerca do referido inciso, ausente os votos dos Min. Ricardo Lewandowski e Min. Roberto Barroso e sem manifestação expressa sobre o assunto da Min. Rosa Weber, ou seja, o resultado de 6 votos favoráveis e manifestação não expressa do Min. Alexandre de Moraes.

9 FERREIRA FILHO, Manoel Gonçalves, Curso de direito constitucional, $38^{\mathrm{a}}$ ed., rev. e atual, São Paulo : Saraiva, 2012 e SILVA, José Afonso da, Curso de Direito Constitucional Positivo, 42a ed. rev. e atual., Salvador : Juspodivm, 2017. 
pode ser razão suficiente para alterar o entendimento acerca dessa questão. Do mesmo modo, Heinen (2010) completa que somente por reforma constitucional poderia ser adotado o referido entendimento diante das suas incongruências, apesar de ele atraente.

Por essa última razão, Alencar (2010) critica a essa adoção pela justificativa da excessiva litigiosidade no Brasil e suas desigualdades processuais inerentes, porque adotar essa postura traz uma ofensa à dignidade da pessoa humana e, em consequência, comprova que a doutrina constitucional ao mesmo que enaltece as garantias fundamentais não se preocupa com sua concretização.

Sgarbossa e Iensue (2017) asseveram dois pontos relevantes. Primeiro, entendem forçoso compreender "suspender a eficácia" como "dar publicidade". Aqui, a posição é diversa daquela explicada por Streck. Isso porque a suspensão da execução não retira a lei do ordenamento, apenas a sua execução está suspensa, ao passo que esses autores afirmam a diferença entre dar simples publicidade e efetivamente fazer com que a norma jurídica não mais produza efeitos, pois suspensa. Também, a abstrativização deste modo violaria o art. 102 par. $2^{\circ}$ da CF pois somente ao controle concentrado a eficácia seria erga omnes.

Streck (2019), outro grande crítico das posições do supremo federal, traz muitas questões relevantes. Inicialmente, argumenta que se o processo existe para preservar direitos, não se pode, em seu nome, fragilizar a si mesmo e, deste modo, atinge o devido processo legal pois retira o interesse de outros sujeitos participarem da discussão democrática do caso. Completa que, além disso, as partes são limitadas, e assim inevitavelmente faria com que aprofundamento da discussão também se limitasse.

Jorge de Souza (2012) constrói o artigo mais robustamente fundamentado quanto à contrariedade ao instituto. Primeiro, justifica que o grande sucesso do modelo de controle incidental nos EUA se deu por conta do stare decisis em que a adoção do entendimento pelas cortes inferiores do que decide a superior é obrigatória, algo que não ocorreu em nossas terras, motivo pelo qual a abstrativização seria um caminho equivocado para a correção desse defeito. Critica a aproximação do controle difuso e concentrado quando da adoção do instituto, porque no controle difuso não haverá coisa julgada quanto à deliberação da matéria constitucional porque é fundamentação da decisão e, também, inevitavelmente a questão prejudicial deverá ter conexão com o pedido do autor da petição inicial e assim há conexão com o caso em específico. Outra complicação é a pretensa ofensa à separação de poderes ao caso, pois o Senado é órgão que representa a população, razão pela qual suprimir tal atribuição é antidemocrático. Por fim, anota um problema formal já que para a construção de uma Súmula Vinculante há necessidade da aprovação do quórum de 2/3 dos ministros e, assim, admitir que determinada tese em controle incidental com maioria absoluta e efeito erga omnes esvaziaria a Súmula Vinculante por completo (uma alternativa criada para o controle difuso, mas que não teve boa repercussão).

Santos (2010) propõe uma ideia concreta em um estudo que compara as vezes em que STF comunicou e o Senado cumpriu a determinação do art. 52, X da CF. Conclui que a grande maioria das vezes fora atendido, porém com ausência de regularidade, alguns períodos o Senado 
edita muito, em outros nada faz.

O último autor, Macêdo (2013), faz pergunta sistemática à abstrativização: quando há declaração por via incidental, se trata de precedente ${ }^{10}$ ou de controle com a pretensa atribuição de abstratividade? Adotar o precedente faz com que a resposta do judiciário se torne mais previsível, com crescimento da segurança jurídica e respeito à isonomia, porém com possível desrespeito das cortes inferiores, diante da ausência da obrigatoriedade vinculatória. Optar pela abstratividade, no entanto, impede que o debate seja mais profundo e plural, impõe uma noção de definitividade e impede a possibilidade de distinção e revogação de um precedente, qualidades que seriam inerentes à evolução do sistema. Sua crítica, portanto, baseia-se na ideia do sistema como um todo e da adoção dos precedentes.

Conhecido todos os autores e todas as críticas possíveis em relação ao instituto, passemos à resposta. Para uma compreensão holística, a resposta estará dentro do próprio texto como um todo só em atenção a cada crítica e ponderação feita acima pelos autores contrários à ideia. Em todos os outros artigos que propõem razões vagas sem apontar precisamente qual o desrespeito à Constituição, como exemplo a violação aos direitos individuais, da dignidade humana, do devido processo legal, ou mesmo do direito fundamental do cidadão, forçoso sua desconsideração. Isso porque é contraditório erigir uma crítica com base nesses fundamentos quando criticam a mesma postura do Supremo Tribunal Federal quando ou definem sua pauta ou julgam determinada questão constitucional. Se estes mesmos que criticam as tomadas de decisões do Tribunal Supremo Federal quando suas razões são vagas e imprecisas e usam das mesmas armas para criticá-los, não temos aqui argumento algum. Se há discricionariedade de lá, havendo discricionariedade de cá, há nada contra nada.

Por tudo, explica-se a adoção da abstrativização do controle incidental e da mutação constitucional do art. 52, X da CF. Certo ou não, ideal ou pernicioso, esse foi o sistema adotado pelo Brasil, mesmo sem o prestígio de todo o complexo formado pelo stare decisis, e interpretá-lo não é um modo de correção do sistema jurídico estrangeiro, mas sim uma compreensão do nosso próprio.

Para cada norma constitucional originária ${ }^{11}$ há em conjunto outras tantas que se agregam ou se opõem a ela com maior ou menor afinidade, razão pela qual a hermenêutica não "adiciona texto", mas integra as normas como parte de um sistema-conjunto e para tanto não é necessária a reforma constitucional, pois não há nenhuma incongruência. As normas constitucionais originárias possuem mesma hierarquia constitucional. Não é o caso de entender "dar publicidade" como sinônimo de "suspender a execução" e menos de confundi-la com "retirar a eficácia", mas sim desvelar o direito como sistema harmônico de normas com valores- não é necessária uma reforma

10 Jurisprudência é um conjunto reafirmado de decisões do tribunal no mesmo sentido; precedente é um caso particular. A diferença é o que se adota como precedente ou jurisprudência. A dificuldade é encontrar a relevante decisão que leva ao precedente. A dificuldade do precedente é estabelecer o que de fato é relevante; da jurisprudência é entender quantas decisões são suficientes para estabelecê-la.

11 Diz-se originária pois é possível a utilização das normas constitucionais originárias como parâmetro de uma emenda constitucional. Porém, o mesmo não é possível em relação a uma norma constitucional originária, ou seja, esta não poderá ser julgada inconstitucional. 
constitucional para tal concepção pois é decorrente do próprio sistema, basta que a interpretação não seja literal. A mutação compreende a norma sob outros olhos com o avanço interpretativo de atribuir ponderações de direitos/princípios, inerente às normas Constitucionais nas ideias de Alexy (2008) ou mesmo reconhecer sua plasticidade inerente como Horta (1992). Presente a hermenêutica (independente da mutação), inevitavelmente tem-se a Constituição como sistema- não com leituras textuais absolutas: nenhum direito é absoluto. Se o limite da própria Constituição são as alterações das cláusulas pétreas, com maior razão a mutação também está limitada a tal disposição. O Senado declara a suspensão da execução, essa é a interpretação.

O crescente número de processos já é uma mudança social suficiente para essa interpretação. Essa excessiva judicialização nada mais é que uma busca de respostas para perguntas que a realidade desjudicializada não responde, mas o judiciário sim, em razão da proibição do non liquet. Além do mais, é ilógico pressupor que o tribunal fosse demandado para analisar a mesma questão por diversas vezes ${ }^{12}$. Mendes (2017) critica que as cortes superiores não podem continuar a ser Cortes de Justiça para casos concretos, pois ficam presos entre a fórmula do artigo e o crescente número de processos. Porém, ainda que se negue tal, existem outras justificativas suficientes para a adoção do instituto da abstrativização e a razão são as mesmas para a adoção dos precedentes judiciais vinculantes e da uniformização da interpretação ${ }^{13}$.

O papel típico do Senado é legislar, ele possui a oportunidade de analisar a constitucionalidade dos projetos legislativos, conforme vimos. Se a inconstitucionalidade passou desapercebida, haverá perda de oportunidade e não há antidemocracia nisto. Se a atribuição do Senado é política (art. 52, X), há desrespeito muito maior do Poder Legislativo ao Judiciário quando deixa de agir em conformidade com o inciso, como vimos. Sarlet (2017) $)^{14}$ entende como um contrassenso a interpretação literal, se não é possível exigir do Poder Legislativo tal atuação, eventual inércia não poderia conduzir a ideia de que a decisão do STF não produziu ou deixou de produzir eficácia vinculante. O estudo feito por Santos (2010) é deveras interessante. No entanto, o artigo apenas analisa números absolutos quanto as resoluções do Senado, sem indicação das comunicações feitas pelo STF. Assim, há possibilidade de ocorrer casos em que o Senado tenha ignorado as comunicações do Tribunal Supremo, o que torna a conclusão do artigo pela ausência mutação constitucional prejudicada. Por outro lado, o Poder Legislativo não fica vinculado à decisão do STF razão pela qual pode, caso queira, agir positivamente e propor uma nova espécie normativa para tentar superar o vício que o Tribunal encontrou ao caso, o chamado efeito backlash (reação legislativa) e essa justificativa é suficiente para prestigiar a qualidade democrática do nosso sistema. Em conclusão, o Judiciário, por sua própria natureza, é inerte: a ideia de que o STF tem

$12 \mathrm{O}$ acervo atual, ou seja, a quantidade de processos que os onze Ministros possuem para decidir, soma em 38.241http://www.stf.jus.br/arquivo/cms/publicacaoBOInternet/anexo/Acervo-Lista_Geral2.xlsx, acesso em 20/05/20.

13 Pode-se citar como exemplo o princípio da igualdade já que os jurisdicionadōs desejam que aos mesmos casos seja dado o mesmo tratamento. Esse desejo cria uma expectativa umbilicalmente vinculada a boa-fé na Administração Pública e da Justiça. Contribui também para maior estabilidade das relações e admite uma confiança nos tribunais para as relações entre os sujeitos o que admite uma maior evolução nessas, entre outras tantas consequências. Portanto, há a concretização desses direitos e não desrespeito conforme afirmam alguns autores.

14 No mesmo sentido: BARCELLOS, Ana Paula de, Curso de direito constitucional, Rio de Janeiro: Forense, 2018, p.. 618 . 
a última palavra é falsa.

Outro argumento contrário à nova interpretação é a fragilização processual diante da pouca participação democrática na discussão do caso, o que tornaria o aprofundamento do discurso como raso e limitado. Porém, não prevalece. A admissão ou não do amicus curiae é admitida em ambas as espécies de controle. Com o CPC/15 e sua difusão dos nos processos, bem como a afetação da questão em repercussão geral, ou mesmo a adoção dos recursos repetitivos, tal argumento perdeu fundamento, hodiernamente o supremo adota em diversos julgados e o próprio texto do art. 138 do CPC/15 não limita sua participação nos processos de controle concentrado. Se também o rol de legitimados do controle concentrado é numerus clausus nem por isso se entende antidemocrático quando somente um deles inaugura o processo. Por exemplo, apesar de ser reconhecida à Defensoria Pública, desde a sua criação, um papel relevantíssimo em defesa dos necessitados não se questiona como violação à democracia no sistema concentrado a sua ausência no art. $103 \mathrm{CF}^{15}$. Em verdade, a razão vai em direção oposta à crítica já que o processo que o STF recebe pela via não concentrada passa por muito maior maturação pois percorre um caminho mais extenso pelos juízos e tribunais, além de geralmente contar com maior tempo de processamento comparado com as ações pela via concentrada.

Com relação aos sistemas difusos e concentrado, seus efeitos e aproximações, a questão é complexa. O sistema pela via incidental deve manter-se diverso daquele pela via principal, por uma razão sistemática. Atribuir os mesmos efeitos a ambos seria um desprestígio à Súmula Vinculante, bem como ao sistema de precedentes, conforme expôs Macêdo (2013) e Jorge de Souza (2012). Para tanto, seria necessário integrar o sistema da adoção da abstrativização sem interferir na importância da Súmula Vinculante e do controle abstrato de constitucionalidade.

Para sua coesão, propõe-se a seguinte interpretação. Quando o STF se incumbe de julgar determinada questão em caráter incidental, teríamos alguns cenários possíveis em relação ao quórum de aprovação. Desta forma, para a integração sistemática da questão caso o quórum alcançasse $2 / 3$ dos seus membros após reiteradas decisões sobre matéria constitucional, poderíamos admitir os mesmos efeitos erga omnes e vinculante, tal qual o adotado pela Súmula Vinculante, ao controle incidental de constitucionalidade. Isso demonstra não somente a maturidade do tema (razão pela qual oito ministros entenderiam que tal pleito deveria ser julgado procedente), como também harmoniza o sistema constitucional como um todo, com os mesmos requisitos da Súmula Vinculante ${ }^{16}$. Por outro lado, nos casos em que o quórum de aprovação for de maioria absoluta, ou mesmo maioria simples, haverá de existir um precedente, com força persuasiva, a ser respeitado pelos tribunais e juízes de todo o sistema. Neste caso, não há impedimento para seu amadurecimento e discussão, porém ao âmbito do tribunal superior, ou seja, esse precedente não retira a capacidade de a corte rejuvenescer seus posicionamentos e aprofundar as suas razões. Se por alguma razão a Súmula Vinculante for excluída do sistema, a questão sobre o quórum aproxima ainda mais o sistema concentrado daquele incidental e os $2 / 3$ não terão mais razão para prevalecer.

15 A defensoria apenas participa da revisão de súmula vinculante do art. $3^{\circ}$ inciso VI da Lei ${ }^{\circ}$ 11.417/06.

16 Art. 103-A da CF. 
Por fim, como a questão da coisa julgada se alterou com o CPC/15, também o controle incidental forma coisa julgada que, ao caso, não se confunde com a transcendência dos motivos determinantes pois estar-se-ia adotando uma coisa julgada incidental, em caso de obediência dos requisitos do art. $503 \S 1^{\circ}$ do CPC, razão pela qual a adstrição do pedido-causa se dá somente no julgamento do pedido principal e não em razão de julgamento da questão prejudicial -não há vinculação nem aos fundamentos, nem o Supremo em relação a suas decisões anteriores. A conexão com o pedido ou não tem relação com a formação do entendimento do Tribunal e do precedente em si e apesar da relação com a matéria em questão, trata-se de um assunto eminentemente crítico a como os precedentes são formados e não como são os efeitos das decisões do tribunal.

\section{CONCLUSÃO}

Por tudo exposto, na medida que o sistema de precedentes avança no complexo constitucional brasileiro, inclusive por meio das normas infraconstitucionais do Código de Processo Civil com o caso dos efeitos vinculantes aos recursos repetitivos de controvérsias, a adoção do sistema de repercussão geral, entre outros fatores, contribuem para a superação da histórica compreensão do art. 52, X da CF e a adoção do sistema da abstrativização do controle incidental pelo STF e o sistema jurídico brasileiro.

Partindo-se da compreensão que a atuação do Senado Federal não é obrigatória, bem como que ele possui sua relevância no processo de construção normativa, o judiciário precisa assegurar que haja respeito às suas decisões e, deste modo, garantir eficácia constitucional, suficiente à conferência da nova interpretação apta a garantir a objetificação do controle incidental. Essa razão garante maior independência entre os poderes e maior autonomia quanto do cumprimento do papel típico de cada um deles, o judiciário julgar e o legislativo legislar.

Exigir interpretação literal é não só infirmar a força da própria decisão do Tribunal Supremo no controle incidental, mas, principalmente, reforçar a ideia de um tribunal como terceira instância de recursos.

A consequência seria atestar a falência do sistema jurídico como um todo. Por essa posição e resposta dada às críticas, bem como a solução ao problema da incompatibilidade com a Súmula Vinculante, o tribunal ao mesmo tempo que procura valorizar e pretender respeito às suas decisões, pode, ao mesmo tempo, refletir sobre tal caso. Nesse ponto pode não só dar uma resposta satisfatória, mas também avançar a ponto de melhorar ainda mais a compreensão daquilo que se entendia ao caso.

Ao fim e ao cabo, a razão do papel do tribunal é agir para o garantir atuação sob o aspecto ao qual fora criado de proteger a constituição e assegurar sua integridade e estabilidade.

Argumentar que seria antidemocrático o respeito ao que o tribunal decide, ao depender das partes que o integram, bem como a via ou o modelo de controle ao qual ele é submetido, significa um mecanismo para diminuir a autoridade das próprias decisões e fazer com que o tribunal tenha que diversas vezes repetir o mesmo entendimento acerca de determinado assunto 
e, por via de consequência, se desgaste e perca tempo em assuntos exauridos. Isso não quer dizer que a própria corte não possa amadurecer os seus entendimentos e evoluir sua jurisprudência, seja ao criar precedentes, alterá-los ou mesmo sinalizar eventual alteração, mas invocar um meio hábil pelo qual as decisões devam ser respeitadas é, ao fim e ao cabo, não entender acerca do pano de fundo da própria decisão em si proferida (a questão material relevante) e sim entender pela não instrumentalidade processual.

\section{REFERÊNCIAS}

\section{Livros}

ALEXY, Robert. Teoria dos Direitos Fundamentais, São Paulo: Malheiros, 2008;

BARCELLOS, Ana Paula de, Curso de direito constitucional, Rio de Janeiro: Forense, 2018;

BARROSO, Luis Roberto, $O$ controle de constitucionalidade no direito brasileiro: exposição sistemática da doutrina e análise crítica da jurisprudência, $7^{\mathrm{a}}$ ed. rev. e atual. São Paulo: Saraiva, 2016;

DANTAS, Paulo Roberto de Figueiredo, Direito Processual Constitucional, $8^{a}$ ed., São Paulo: Saraiva Educação, 2018;

DIMOULIS, Dimitri, Curso de processo constitucional: controle de constitucionalidade e remédios constitucionais, $4^{\mathrm{a}}$ ed. rev., atual. e ampl, São Paulo: Atlas, 2016;

FERREIRA FILHO, Manoel Gonçalves, Curso de direito constitucional, $38^{\mathrm{a}}$ ed., rev. e atual, São Paulo : Saraiva, 2012;

KELSEN, Hans, Teoria pura do direito, $7^{\mathrm{a}}$ ed., São Paulo: Martins Fontes, 2006;

MARTINS, Flávio, Curso de Direito Constitucional, $1^{\text {a }}$ ed., São Paulo: Editora, Revista dos Tribunais, 2017;

MENDES, Gilmar Ferreira, Curso de direito constitucional, $12^{\mathrm{a}}$ ed. rev. e atual., São Paulo: Saraiva, 2017;

MORAES, Alexandre de, Direito Constitucional, 33a ed. rev. e atual., São Paulo: Atlas, 2017; PAULO, Vicente, Direito Constitucional Descomplicado, $15^{\mathrm{a}}$ ed. rev. e atual., Rio de Janeiro: Forense, São Paulo: MÉTODO, 2016;

SARLET, Ingo Wolfgang, Curso de direito constitucional, $6^{a}$ ed., São Paulo: Saraiva, 2017; SILVA, José Afonso da, Curso de Direito Constitucional Positivo, 42 ${ }^{\mathrm{a}}$ ed. rev. e atual., Salvador : Juspodivm, 2017;

SIMÃO, Calil, Elementos do sistema de controle de constitucionalidade, $3^{\text {a }}$ ed., São Paulo: Saraiva, 2015;

SLAIBI FILHO, Nagib, Direito Constitucional, $3^{\text {a }}$ ed., Rio de Janeiro: Forense, 2009; 
STRECK, Lenio Luiz, Jurisdição constitucional, 6ª ed., Rio de Janeiro: Forense, 2019.

Artigos

ALENCAR, Rosmar Antonni Rodrigues Cavalcanti de, Direitos Fundamentais e jurisdição constitucional: proclamação "retórica" v. efetividade concreta, Revista de Processo, vol. 184, Jun / 2010, p. 363 - 374;

BULOS, Uadi Lamêgo, Da reforma à mutação constitucional, Revista de informação legislativa, v. 33, n. 129, jan./mar. 1996, p. 25-43;

HEINEN, Juliano, Abstrativização do Controle Difuso ou Difusão de uma Abstrativização Teórica?, Revista da Procuradoria-Geral do Estado do Rio Grande do Sul, Vol. 9, n.24, Porto Alegre, p. 27-37, 2010, p. 27-37;

HORTA, Raul Machado, Permanência e mudança na Constituição, Revista de Informação legislativa, v. 29, n. 115, jul./set. 1992, p. 5-25;

JORGE DE SOUZA, Léa Émile Maciel, A objetivação da decisão do supremo tribunal federal no controle concreto de constitucionalidade, Revista de Direito Constitucional e Internacional, vol. 81, Out - Dez /2012, p. 13 - 35;

MACÊDO, Lucas Buril de, Duas notas sobre o art. 52, X, da Constituição Federal e a sua pretensa mutação constitucional, Revista dos Tribunais, Revista de Processo, Vol. 215, Jan/2013, p. $437-461$

QUINAUD PEDRON, Flavio, O julgamento da Reclamação no 4.335-AC e o papel do Senado Federal no controle difuso de constitucionalidade, RIL Brasília a. 52, n.207, jul./set. 2015, p. 213-237;

SANTOS, Carlos Victor Nascimento dos, Mutação constitucional do controle difuso no Brasil? Uma análise do papel do Senado diante do art. 52, X, da Constituição, Coleção Jovem Jurista, v. 1., Rio de Janeiro: Escola de Direito da Fundação Getulio Vargas, 2010, p.151-202;

SGARBOSSA, Luis Fernando e IENSUE,Geziela, Algumas reflexões críticas sobre a tese da "abstrativização" do controle concreto de constitucionalidade no Supremo Tribunal Federal (STF), Seqüência UFSC, n. 75, abr/2017, p.79-104.

\section{Legislação}

BRASIL, Acervo processual do Supremo Tribunal Federal, disponível em: $<$ http://www.stf.jus.br/ arquivo/cms/publicacaoBOInternet/anexo/Acervo-Lista_Geral2.xlsx >, acesso em 20/05/20;

; Constituição da República Federativa do Brasil de 1988. Disponível em: <http://www. planalto.gov.br/ccivil_03/constituicao/constituicao.htm>;

; Lei $\mathrm{n}^{\circ} 9.868$ de 10 de novembro de 1999. Disponível em: < http://www.planalto.gov.br/ ccivil_03/leis/19868.htm>; 
; Lei ${ }^{\circ} 9.882$ de 3 de dezembro de 1999. Disponível em: < http://www.planalto.gov.br/ ccivil_03/leis/19882.htm>;

; Código de Processo Civil, Lei no 13.105 de 16 de março de 2015. Disponível em: < http:// www.planalto.gov.br/ccivil_03/_ato2015-2018/2015/lei/113105.htm>;

; Regimento interno da câmara dos deputados, disponível em: <https://www2.camara.leg. br/atividade-legislativa/legislacao/regimento-interno-da-camara-dos-deputados/arquivos-1/ RICD\%20atualizado\%20ate\%20RCD\%206-2019.pdf>, acesso em 05/05/20;

; Regulamento do Senado Federal, disponível em: <http://legis.senado.leg.br/comissoes/ download?tp=atribuicoes\&colegiado=34>, acesso em: 05/05/20.

Decisões

BRASIL. Supremo Tribunal Federal, Rcl No 4335 AC, rel. Min. Gilmar Mendes, Data de Julgamento: 20/03/2014;

; Supremo Tribunal Federal, ADI No 4071 AgRg/DF, rel. Min. Menezes Direito, Data de julgamento: 22.04.2009;

; Supremo Tribunal Federal, ADI No 3406/RJ e ADI No 3470/RJ, rel. Min. Rosa Weber, Data de julgamento: 29.11.2017.

Recebido em:11/05/2020

Aprovado em :01/06/2020 